\title{
INTRALESIONAL STEROID INJECTION AND GOLFER'S ELBOW: A PROSPECTIVE STUDY
}

Maruthi C. V1, Shivanna ${ }^{2}$

\section{HOW TO CITE THIS ARTICLE:}

Maruthi C. V, Shivanna. "Intralesional Steroid Injection and Golfer's Elbow: A Prospective Study". Journal of Evolution of Medical and Dental Sciences 2015; Vol. 4, Issue 74, September 14; Page: 12880-12883,

DOI: $10.14260 /$ jemds/2015/1857

ABSTRACT: Golfers elbow is the soft tissue disorder seen in the elbow joint along the medial side. It's and over use disorder of the forearm, wrist and fingers. Here is a study conducted by us to know the effect of intralesional steroid in cases suffering from golfers elbow. 9 cases of golfers elbow were managed with intralesional steroid between August 2014 and April 2015. And followed at 6, 12 weeks and results were evaluated using Nirschl grading system. We achieved grade 5 in two grade six in 5 and grade 7 in two. CONCLUSION: We conclude that golfer's elbow is the soft tissue disorder. Injecting Intralesional steroid will not give significant relief to the patients suffering from golfers elbow and it the procedure is usually associated with complications.

KEYWORDS: Golfers elbow, intralesional steroid, Nirschl grading system.

INTRODUCTION: Medial epicondylitis accounts for only 10-20\% of all epicondylitis diagnoses.[1] Golfers elbow is the soft tissue disorder seen in the elbow joint along the medial side. It's an over use disorder of the forearm, wrist and fingers. Here is a study conducted by us to know the effect of intralesional steroid in cases suffering from golfers elbow.

MATERIALS AND METHODS: 9 cases of golfers elbow were managed with intralesional steroid between August 2014 and April 2015. And followed at 6, 12 weeks and results were evaluated using Nirschl grading system [Table 1].[2]

\begin{tabular}{|c|l|}
\hline GRADE & \multicolumn{1}{|c|}{ Description } \\
\hline 1 & Mild pain with exercise, resolves within 24 hours \\
\hline 2 & Pain after exercise, exceeds 48 hours \\
\hline 3 & Pain with exercise, does not alter activity \\
\hline 4 & Pain with exercise, alters activity \\
\hline 5 & Pain with heavy activities of daily living \\
\hline 6 & Pain with light activities of daily living, intermittent pain at rest \\
\hline 7 & Constant pain at rest, disrupts sleeps \\
\hline & Table 1: Nirschl grading system \\
\hline
\end{tabular}

OBSERVATIONS AND RESULTS: In our study 4(56.67\%) patients were between 35 and 40 years, $1(26.66 \%)$ between 41 and 45 years and 1(16.67\%) between 46 and 50 years. All of them were males $6(100 \%)$. The right side was affected in all six cases $(100 \%)$. Radio-logically sclerosis at the medial epicondyle was seen in all the cases. 


\section{ORIGINAL ARTICLE}

All were treated with analgesics, physiotherapy and rest for few months and were not relived with the symptoms.

Injection Technique: By using $2 \mathrm{ml}$ disposable syringe $1 \mathrm{ml}$ Tramcelone acetate and $1 \mathrm{ml}$ Lignocaine $1 \%$ is loaded. Place the patient in a comfortable supine position. This aids relaxation and guards against possible fainting. Flex the affected elbow to 90 degrees with 90 degrees of shoulder rotation. Mark the medial epicondyle and the olecranon process. Followed sterile precautions throughout the procedure. Clean the skin carefully with antiseptic agents. Ethyl chloride may be applied to the skin for anesthesia. Insert a 5/8-inch, 25-gauge needle perpendicular to the skin, 1/2 inch distal to the center of the epicondyle or at a 45 -degree angle, to a depth of $3 / 8$ to 5/8inch. Inject $1 / 2 \mathrm{~mL}$ of lidocaine subcutaneously and $1 / 2 \mathrm{~mL}$ at the tendon/fat. Inject at the most tender point. Infiltrate and the corticosteroid mixture deeply at the tenoperiosteal junction. A painful reaction to injection or firm resistance during injection suggests that the needle is too deep and is within the body of the tendon; withdraw the needle 1/8inch if this occurs. The needle should move freely with skin traction if the tip is above the tendon; conversely, the needle sticks in place if the tip is within the body of the tendon. Always inject the corticosteroid at the tissue plane between the subcutaneous fat and the tendon. At the end of the injection, withdraw the needle swiftly and apply light pressure over the needle site.[2]

Follow up: Patients were given B-complex supplements for next follow-up as placebo, and no one was advised to take any kind of analgesics. Patients were followed at 6 and 12 weeks.

Complications: Discolouration of the skin was seen in 6 of our patients, Ulnar nerve injury in two and severe tenderness along the medial epicondyle in one of our patients.

Results were evaluated using Nirschl grading system. We achieved grade five in two grade six in five and grade seven in two of our patients [Table 2].

\begin{tabular}{|c|c|c|}
\hline GRADE & DESCRIPTION & $\begin{array}{c}\text { OBSERVATIONS } \\
\text { AT 6 AND 12 } \\
\text { WEEKS }\end{array}$ \\
\hline 1 & Mild pain with exercise, resolves within 24 hours \\
\hline 2 & Pain after exercise, exceeds 48 hours \\
\hline 3 & Pain with exercise, does not alter activity & \\
\hline 4 & Pain with exercise, alters activity & 2 \\
\hline 5 & Pain with heavy activities of daily living \\
\hline 6 & Pain with light activities of daily living, \\
intermittent pain at rest & 2 \\
\hline 7 & Constant pain at rest, disrupts sleeps & \\
\hline \multicolumn{2}{|c|}{ Table 2: The results according to the Nirschl grading system } \\
\hline
\end{tabular}




\section{ORIGINAL ARTICLE}

DISCUSSION: Golfer's elbow is a condition that causes pain where the tendons of forearm muscles attach to the medial epicondyle of elbow. The pain might radiate to forearm and wrist. It's not limited to golfers. Tennis players and others who repeatedly use their wrists or clench their fingers also can develop golfer's elbow. The symptoms are Pain on the inner side of elbow. Sometimes the pain extends along the inner side of forearm. Pain typically worsens with certain movements. Other symptoms are stiffness of the elbow joint, weakness in hands and wrists and numbness or tingling.

The pain of golfer's elbow can come on suddenly or gradually. The pain might worsen while swinging a golf club or racket, Squeezing or pitching a ball, shaking hands, lifting weights, Picking up something with palm down and Flexing wrist.

Many activities can lead to golfer's elbow, including: golf, racket sports, throwing sports and weight training, bending and straightening elbow can cause golfer's elbow. This includes painting, raking, and hammering, chopping wood, using a computer, doing assembly-line work and cooking. The activity generally needs to be done for more than an hour a day on many days to cause a problem. The risk factors for golfers elbow are age 40 or older, performing repetitive activity at least two hours a day, obese and smoking. Left untreated, golfer's elbow can cause: chronic elbow pain, restricted range of motion and fixed flexion contracture of the elbow joint. The most common site of pathology is the interface between the pronator teres and the flexor carpi radialis origin. Diagnosis is by medical history and a physical examination. To evaluate pain and stiffness apply pressure to the affected area. Golfer's elbow test: pronate and flex the wrist and forearm against resistance. A result is positive when pain is located over the attachment of the wrist flexor muscles on the medial aspect of the elbow. ${ }^{[2]}$ An X-ray can help to rule out other causes of elbow pain, such as a fracture or arthritis. Sclerosis of the medial border of the medial epicondyle is seen in most of the cases. In our study we observed in all our nine cases.

Prevention: Strengthen forearm muscles, stretching before activity. Lift the objects properly. Educating the patients, when to rest after certain use.[3]

Treatment: There are various modalities of treatment for golfers elbow like Rest, Ice the affected area, Analgesics, Brace, Stretching and strengthening the flexor muscles, Reduce the load on elbow tendons.[4] Surgery is seldom necessary. But if your signs and symptoms don't respond to conservative treatment in six to 12 months, surgery may be an option..$^{[5]} \mathrm{A}$ new procedure involves minimally invasive, ultrasound-guided removal of scar tissue in the region of the tendon pain. Other treatments used include corticosteroid injections, which have not been shown to be an effective longterm treatment.[6,7] And intralesional steroids has been associated with more of complications like discoulouration of skin, injury to the ulnar nerve and persistent bony pain, as proved by our study and the results are comparable to standard studies. A newer treatment being tried is platelet-rich plasma. This involves drawing a small amount of patient's blood, spinning it down and injecting it into the tender area.

CONCLUSION: We conclude that golfer's elbow is the soft tissue disorder. Injecting Intralesional steroid will not give significant relief to the patients suffering from golfers elbow and the procedure is usually associated with complications. 


\section{ORIGINAL ARTICLE}

\section{REFERENCES:}

1. Plancher KD, Halbrecht J, Lourie GM. Medial and lateral epicondylitis in the athlete. Clinicle Sports Medicine. 1996 Apilr. 15(2):283-305.

2. Nirschl RP. Prevention and treatment of elbow and shoulder injuries in the tennis player. Clinicle Sports Medicine. 1988 Apilr. 7(2): 289-308.

3. Nirshal RP. Muscle and tendon trauma: tennis elbow. The Elbow and Its Disorders. Philadelphia, Pa: WB Saunders Co; 1993. 481-96.

4. Labelle H, Guibert R. Efficacy of diclofenac in lateral epicondylitis of the elbow also treated with immobilization. The University of Montreal Orthopaedic Research Group. Arch Fam Med. 1997 May-Jun. 6(3): 257-62.

5. Kwon BC, Kwon YS, Bae KJ. The Fascial Elevation and Tendon Origin Resection Technique for the Treatment of Chronic Recalcitrant Medial Epicondylitis. Am J Sports Med. 2014 Apr 23. 42(7): 1731-1737.

6. Stahl S, Kaufman T. The efficacy of an injection of steroids for medial epicondylitis. A prospective study of sixty elbows. J Bone Joint Surg Am. 1997 Nov. 79(11): 1648-52.

7. Verhaar JA, Walenkamp GH, van Mameren H. Local corticosteroid injection versus Cyriax-type physiotherapy for tennis elbow. J Bone Joint Surg Br. 1996 Jan. 78(1): 128-32.

\section{AUTHORS:}

1. Maruthi C. V.

2. Shivanna

\section{PARTICULARS OF CONTRIBUTORS:}

1. Assistant Professor, Department of Orthopaedics, Chamarajanagar Institute of Medical Sciences, Chamarajanagar.

2. Senior Resident, Department of Orthopaedics, Chamarajanagar Institute of Medical Sciences, Chamarajanagar.
FINANCIAL OR OTHER COMPETING INTERESTS: None
NAME ADDRESS EMAIL ID OF THE CORRESPONDING AUTHOR:

Dr. Maruthi C. V, Assistant Professor, Department of Orthopaedics, Chamarajanagar Institute of Medical Sciences, Chamarajanagar-571313, India.

E-mail: orthocvmaruthi@gmail.com

Date of Submission: 28/08/2015. Date of Peer Review: 29/08/2015. Date of Acceptance: 08/09/2015. Date of Publishing: 12/09/2015. 